\title{
Characterisation of centromere (kinetochore) antigen reactive with sera of patients with a scleroderma variant (CREST syndrome)
}

\author{
M. NISHIKAI, Y. OKANO, H. YAMASHITA, AND M. WATANABE
}

From the Rheumatology Section, Department of Internal Medicine, Second Tokyo National Hospital, Tokyo, Japan

SUMMARY Anticentromere (kinetochore) antibody is the marker antibody in CREST syndrome, but the precise molecular composition of the partner antigen has been poorly defined. This report describes for the first time a procedure for the successful extraction and biochemical characterisation of the centromere antigen molecule. The centromere antigen was extracted with $4 \mathrm{M} \mathrm{NaCl}$ solution. The molecular weight of the partner antigen of the centromere antibody was determined to be 70000 daltons by the SDS-PAGE and immunoblotting methods. A Sephacryl S-300 column experiment confirmed these results. Centromere antigenic activity was preserved at pHs between 3 and 11 and was resistant to three enzymes, trypsin, RNase, and DNase.

Key words: antinuclear factors, autoantibody, connective tissue disease, collagen disease, antigens.

CREST syndrome is a variant of scleroderma characterised by calcinosis, Raynaud's phenomenon, oesophageal hypomotility, sclerodactyly, and telangiectasia. Recently Moroi and his coworkers $^{12}$ reported a new autoantibody, the anticentromere (kinetochore) antibody, which is found mainly in the sera of patients with CREST syndrome. Because the centromere antigen is unextractable by physiological saline solution, its extraction and characterisation have been unsuccessful. We describe here for the first time a successful extraction procedure and the biochemical characterisation of the partner antigen of the centromere antibody.

\section{Materials and methods}

Patients' sera. Three reference sera containing anticentromere antibody were kindly provided by $\mathrm{Dr} \mathrm{Y}$. Moroi from among the sera of the patients with CREST syndrome who visited the Second Tokyo National Hospital. It was confirmed that anticentromere antibodies are also found in our 16 Japanese ment of Internal Medicine, Second Tokyo National Hospital, 2-5-1 Higashigaoka, Meguroku, Tokyo, Japan 152. patients with incomplete CREST syndrome or other connective tissue diseases with Raynaud's phenomenon (Table 1) as described in Caucasian population. ${ }^{2-7}$ Patients with incomplete CREST syndrome were defined as those who fulfil three or four of the five symptoms or findings

Table 1 Diagnoses of 16 patients with anticentromere antibody

\begin{tabular}{llll}
\hline $\begin{array}{l}\text { Patient } \\
\text { no. }\end{array}$ & Sex & Age & Diagnosis \\
\hline 1 & & \\
2 & M & 32 & Incomplete CREST syndrome \\
3 & F & 39 & Incomplete CREST syndrome \\
4 & F & 47 & Incomplete CREST syndrome \\
5 & M & 56 & Incomplete CREST syndrome \\
6 & F & 68 & Incomplete CREST syndrome \\
7 & F & 73 & Incomplete CREST syndrome \\
8 & F & 71 & Incomplete CREST syndrome \\
9 & F & 30 & Incomplete CREST syndrome \\
10 & F & 74 & Raynaud's and Sjögren's \\
11 & F & 64 & Raynaud's and Sjögren's \\
12 & F & 55 & Raynaud's and Sjögren's \\
13 & F & 59 & Raynaud's and RA \\
14 & F & 54 & Raynaud's and SLE \\
15 & F & 56 & Raynaud's alone \\
16 & F & 70 & RA and Sjögren's \\
\hline
\end{tabular}

"Rheumatoid arthritis

${ }^{+}$Systemic lupus erythematosus 
mentioned above. Systemic lupus erythematosus (SLE) and rheumatoid arthritis (RA) were diagnosed according to the criteria of the American Rheumatism Association. ${ }^{89}$ Sjögren's syndrome was diagnosed by the criteria of the Research Committee for Sjögren's Syndrome of the Ministry of Health and Welfare, Japan, ${ }^{10}$ which are the modified criteria by Shearn. ${ }^{11}$

Immunofluorescence study. The anticentromere antibodies in the patients' sera were detected by an indirect immunofluorescence technique using cultured human epithelial cell lines (HEp-2 cells) (Kallstad, Chaska, Mn, USA) as substrate.

Preparation of crude centromere antigen. Acetone-treated rabbit or calf thymus powder (PelFreeze, Rogers, AR, USA) was used as the source of the centromere antigen. The extraction of the centromere antigen from $5 \mathrm{~g}$ of the thymus powder was carried out with 20 volumes of $4 \mathrm{M} \mathrm{NaCl}-0.01$ $\mathrm{M}$ sodium phosphate buffer at $\mathrm{pH} 7 \cdot 4$ for 16 hours at $4^{\circ} \mathrm{C}$ with gentle stirring with a magnet stirrer. This 4 $\mathrm{M} \mathrm{NaCl}$ extract was dialysed overnight against 20 volumes of $0.01 \mathrm{M}$ phosphate buffered saline (PBS)

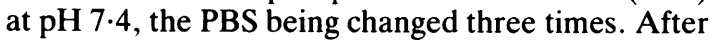
the dialysis this material was centrifuged with a Hitachi RPR-12 Rotor (Hitachi Koki, Tokyo, Japan) at $10000 \mathrm{rpm}$ for $30 \mathrm{~min}$ at $4^{\circ} \mathrm{C}$. The supernatant was concentrated up to $50 \mathrm{mg}$ protein/ $\mathrm{ml}$ with an Amicon Hollow Fiber Concentrator DC2 and a Minicon B15 concentrator (Amicon, Lexington, Mass, USA). Extraction of the centromere antigen with isotonic saline solution, $6 \mathrm{M}$ urea and $1 \%$ sodium dodecylsulphate (SDS) was also tried.

Absorption study. $0 \cdot 1 \mathrm{ml}$ of a 1:400 dilution of the anticentromere antibody-positive serum was mixed with $4,2,1,0.5,0.1 \mathrm{mg}$ of the crude centromere antigen and PBS and incubated for 48 hours at $4^{\circ} \mathrm{C}$. After centrifugation of the solutions for $30 \mathrm{~min}$ at $10000 \mathrm{rpm}$ at $4^{\circ} \mathrm{C}$ the supernatant was tested for remaining anticentromere activity by an indirect immunofluorescence test employing HEp-2 cells.

Purification of centromere antigen. The immunoaffinity column method was used for this purpose. Normal human IgG and IgG containing anticentromere antibody were prepared with a DEAE-cellulose column from $20 \mathrm{ml}$ of pooled normal human sera and from $20 \mathrm{ml}$ of serum from a patient with CREST syndrome respectively. The patient's serum did not contain any other immunofluorescent antibodies in routine tests using rat liver cells as substrate or any precipitating antibodies using the double immunodiffusion technique. Each IgG was coupled to cyanogen bromide $(\mathrm{CNBr})$ activated Sepharose 4B beads (Pharmacia, Uppsala, Sweden) as described previously. ${ }^{12}$ The crude centromere antigen was loaded and eluted with PBS through a normal human IgG coupled $\mathrm{CNBr}$ activated Sepharose column to remove nonspecifically adsorbed antigens which have affinity for normal human IgG. The eluate was poured onto the anticentromere column and the column was eluted with PBS at $4^{\circ} \mathrm{C}$. The adsorbed centromere antigen was detached with $6 \mathrm{M}$ urea, which does not inactivate the centromere antigen. The eluate was dialysed against PBS and concentrated.

SDS-polyacrylamide gel electrophoresis. SDSpolyacrylamide slab gel electrophoresis (SDSPAGE) was carried out as described previously. ${ }^{12}$ Beta-galactosidase (130 000), bovine serum albumin $(69000)$, bovine gamma globulin $(50000$ and $25000)$, trypsin $(24000)$, and sperm whale myoglobin $(17$ 200) (all from Sigma, Saint Louis, Mo, USA) were used as markers for the molecular weights, which are expressed in daltons.

Immunoblotting study. The immunoblotting procedures were carried out according to the method of Towbin et al. ${ }^{13}$ Bovine IgG was used as the marker for molecular weight.

Gel chromatography. Sephacryl S-300 Superfine (Pharmacia, Uppsala, Sweden) was packed in a Pharmacia KP column $(2 \times 90 \mathrm{~cm})$. Blue dextran (2 000000$)$, thyroglobulin $(640000)$, bovine $\mathrm{IgG}$ (150 000), sperm whale myglobin (17 200) (all from Sigma, Saint Louis, Mo, USA) were used as markers for molecular weight. $50 \mathrm{mg}$ of the crude centromere antigen protein was fractionated with a Pharmacia Fraction Collector FRAC-300 (Pharmacia, Uppsala, Sweden). Each separated eluate sample $(5 \mathrm{ml})$ was concentrated to $0.2 \mathrm{ml}$ with the Minicon concentrator, and the antigenic activity of the centromere antigen was tested by the immunoblotting procedure.

Enzyme treatment. The enzyme treatment of the centromere antigen with trypsin, RNase A, DNase I (all from Sigma, Sint Louis, Mo. USA) was carried out as described previously. ${ }^{12}$ Each enzyme substrate ratio was $1: 5$ by weight. Incubation was performed for $1 \mathrm{~h}$ at $37^{\circ} \mathrm{C}$.

pH stability. $\mathrm{pH}$ stability was tested between $\mathrm{pH} 3$ and $\mathrm{pH} 11.0 \cdot 1 \mathrm{M}$ acetate buffer was used at $\mathrm{pH} 3,4$, and $5 ; 0 \cdot 1 \mathrm{M}$ sodium phosphate buffer was used at pH 6, 7 and 8 ; and $0 \cdot 1 \mathrm{M}$ bicarbonate buffer was used at $\mathrm{pH} \mathrm{9,10} \mathrm{and} 11.1 \mathrm{ml}$ of crude centromere antigen $(20 \mathrm{mg}$ protein $/ \mathrm{ml})$ was dialysed overnight against each buffer at $4^{\circ} \mathrm{C}$. Each antigen was redialysed against $\mathrm{PBS} \mathrm{pH} 7 \cdot 4$, and after centrifugation the antigenic activity of the supernatants was tested with the immunoblotting technique.

Species specificity. In order to study the species specificity of the centromere antigen, the crude calf and rabbit thymus antigens were compared. 
Double immunodiffusion. This was performed as described previously. ${ }^{12}$

Protein concentration. The Biuret reaction was used for the estimation of the protein concentration.

\section{Results}

Extraction of the centromere antigen. The PBS, $6 \mathrm{M}$ urea, $1 \% \mathrm{SDS}$, and $4 \mathrm{M} \mathrm{NaCl}$ solutions were tested for extraction of the centromere antigen, and it was demonstrated that only the $4 \mathrm{M} \mathrm{NaCl}$ solution successfully extracted this antigen. The $4 \mathrm{M} \mathrm{NaCl}$ solution showed better extraction capacity than $2 \mathrm{M}$, $1 \mathrm{M}$, or $0.5 \mathrm{M} \mathrm{NaCl}$ solution. Preservation of the antigenic activity of the centromere antigen after exposure to $4 \mathrm{M} \mathrm{NaCl}$ solution was demonstrated by the absorption test (Fig. 1) and subsequent immunoblotting tests (Figs. 3, 4).

Characterisation of the centromere antigen. The immunoaffinity column-purified centromere antigen appeared as a 70000 dalton protein band (CREST70) by SDS-PAGE in the presence of 2mercaptoethanol (Fig. 2), and this band showed centromere-antigenic activity in the immunoblotting experiment (Fig. 4). This result was confirmed with sera from three different patients which contained anticentromere antibody. The Sephacryl S-300 column experiment also showed that the molecular weight of the centromere antigen is around 70000 daltons after $4 \mathrm{M} \mathrm{NaCl}$ treatment of the antigen (Fig. 3).

Enzyme treatment of the centromere (CREST-70) antigen. The RNase and DNase did not affect the CREST-70-antigenic activity in the immunoblotting experiments. Trypsin degraded the CREST-70 antigen molecule to 24000 daltons, but the antigenic activity was unaffected. These results mean that the CREST-70 antigen does contain protein as a part of its molecular structure, as suggested previously, ${ }^{1}$ but

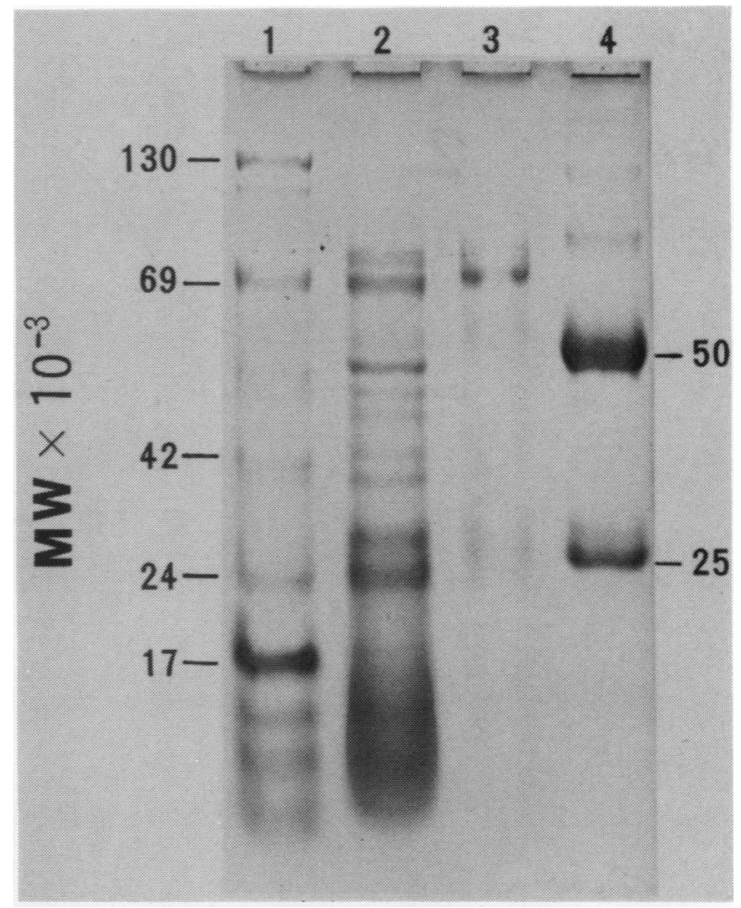

Fig. 2 Coomassie brilliant blue staining patterns in SDS-PAGE. Lane 1: marker proteins. Lane 2: crude centromere antigen. Lane 3: purified centromere antigen. Lane 4: bovine IgG.

that the true antigenic site may not reside in the trypsin-sensitive protein portion.

pH stability. The antigenic activity in immunoblotting tests of the CREST-70 antigen was equally great at $\mathrm{pH}$ values between 3 and 11 .

Species specificity. The CREST-70 antigenic activity was seen in the 70000 daltons protein band in both the calf and rabbit antigens.

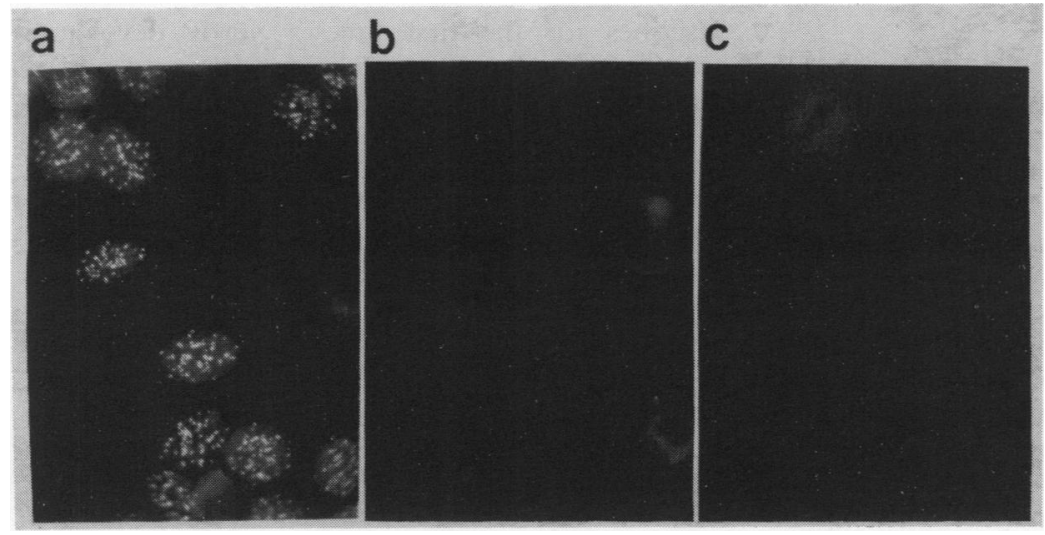

Fig. 1 (a) Anticentromere staining pattern (control). (b) Partially absorbed anticentromere staining. (c) Complete absorption of the anticentromere staining. 


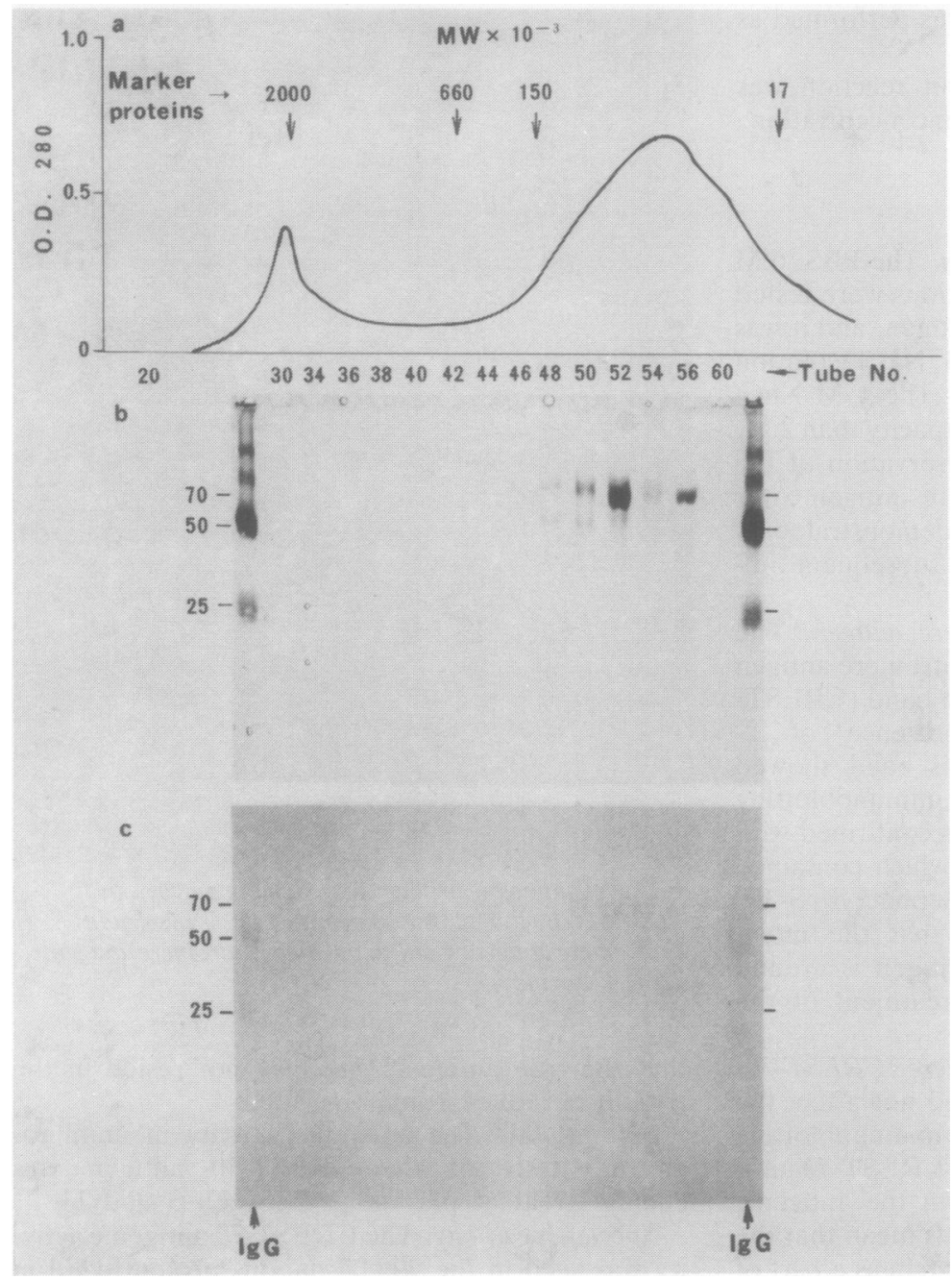

Fig. 3 (a) Sephacryl S-300 gel chromatogram of the crude centromere antigen in the absence of SDS and 2-mercaptoethanol. (b) $S D S-P A G E$ results with concentrated materials in tubes No. 30 to 60 in Fig. $3 a$. Coomassie brilliant blue $G-250$ was used for the staining of the proteins. (c) Immunoblotting experiment using the gel under the same conditions as in

Fig. $3 b$. The anticentromere antigenic activity is shown at the position of around $M W 70000$ in the Sephacryl $S$-300 column chromatogram (Fig. 3a), showing that the molecular weight of the CREST-70 antigen is unchanged in the presence and absence of SDS and 2-mercaptoethanol.

\section{Discussion}

Since the first description of the anticentromere antibody in $1980^{1}$ it has been established with some exceptions that this antibody is the marker antibody of the CREST variant of scleroderma. In the main this was confirmed in our Japanese patients with positive anticentromere antibody. Although it had been demonstrated by the indirect immunofluorescence method ${ }^{1}$ that the partner antigen is located in the centromere (kinetochore) portion of the chromosome, the precise molecular components of the centromere antigen have been poorly defined. The reason for this was the difficulty in the extraction of the centromere antigen. This report describes for the first time a newly developed procedure for the successful extraction and partial characterisation of the centromere antigen molecule (CREST-70).

The CREST-70 antigen showed the same molecular weight as the $\mathrm{Scl}-70,{ }^{14}$ which is an additional scleroderma-related autoantigen. But it is clear that the CREST-70 antigen is different from the Scl-70 antigen in immunofluorescent staining pattern, reaction to enzymes, solubility, and $\mathrm{pH}$ stability. Mckeon $e t$ al. ${ }^{15}$ recently described an autoantibody which specifically recognised the nuclear envelope of Chinese hamster ovary (CHO) cells in the serum of a patient with linear scleroderma. Interestingly, this antibody bound the 70000 daltons nuclear 


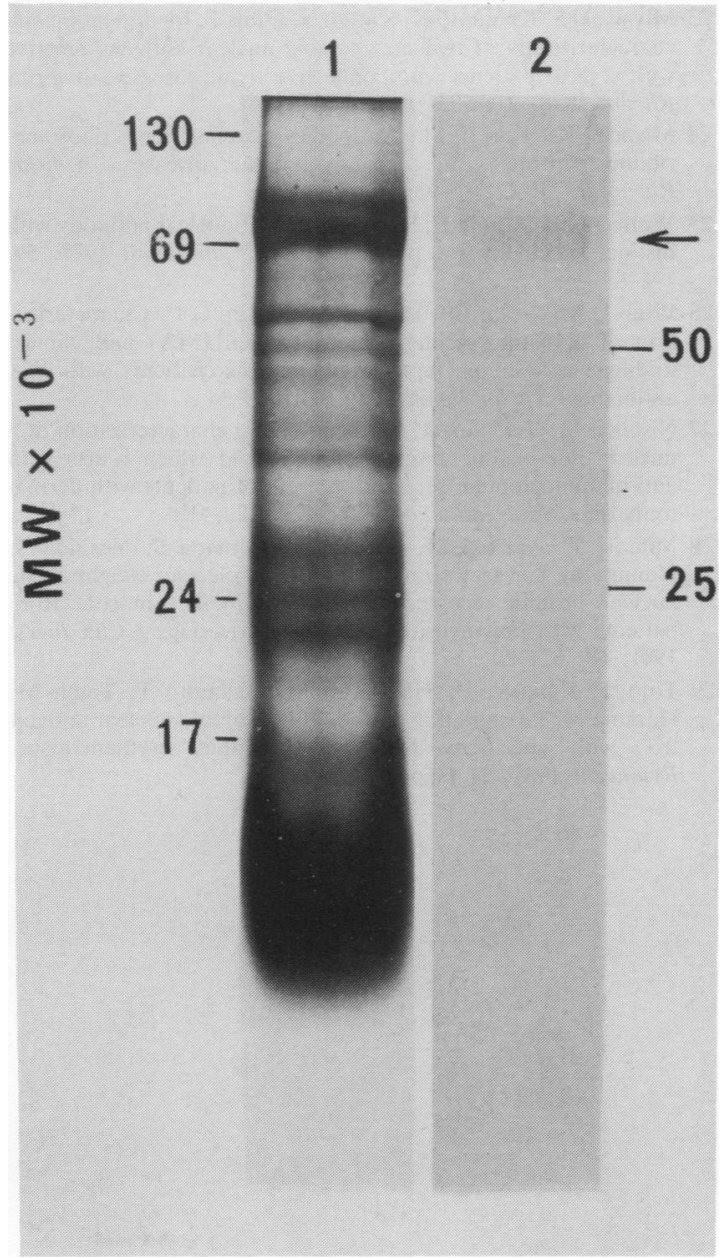

Fig. 4 Lane 1: crude centromere antigen in SDS-PAGE. Lane 2: immunoblotting experiment using the gel under the same conditions as in lane 1 . The arrow denotes the antigenic activity of the centromere antigen (CREST-70).

lamin protein. It may be necessary further to test its identity with the CREST-70 antigen, because Moroi et al. ${ }^{16}$ have already reported that in interphase nuclei of $\mathrm{CHO}$ or Ramos cells the centromereantigenic foci were usually associated with the inner surfaces of the nuclear envelope.

Recently Habets and his coworkers ${ }^{17}$ reported an additional antigen of molecular weight 70000 (MCTD-70) that is reactive mainly with the sera of patients with mixed connective tissue disease (MCTD). The MCTD-70 antigen is also unextractable with PBS and is similar in this respect to the
CREST-70 antigen. The CREST-70 antigen, however, appears to be different from the MCTD-70 antigen, because the MCTD-70 antigen is reported to be found mainly in MCTD patients, and the antigen is sensitive to protease.

The CREST-70 antigen molecule is unique in respect of its toughness. All of the autoantigens described recently, such as $\mathrm{Sm},{ }^{18}$ nuclear RNP, ${ }^{19}$ Ro/SSA, ${ }^{20} \mathrm{La} / \mathrm{SSB}^{21} 22 \mathrm{Mu} / \mathrm{tRNP},{ }^{23}{ }^{24} \mathrm{Sci}-70,{ }^{14}$ PM- $1,{ }^{25} \mathrm{MA},{ }^{26} \mathrm{Jo}-1,{ }^{12} \mathrm{Mi}-1,{ }^{27} \mathrm{Ku},{ }^{28}$ and $\mathrm{Ki}^{29}$ are sensitive to trypsin or RNase. In contrast, the CREST-70-antigenic site is resistant to all of the three enzymes, trypsin, DNase and RNAse, though its molecular size is degraded by trypsin. Further study is needed to define more precisely the nature of the CREST-70 antigenic site. In addition the CREST-70 antigenic activity was preserved at $\mathrm{pH} 3$ and $\mathrm{pH} 11$. This characteristic is also unique because all of the soluble antigens mentioned above lose their antigenic activity at $\mathrm{pH} 3$ and $\mathrm{pH} 11$.

\section{References}

1 Moroi Y, Peebles C, Fritzler M J, Steingerwald J, Tan E M. Autoantibody to centromere (kinetochore) in scleroderma sera. Proc Natl Acad Sci USA 1980; 77: 1627-31.

2 Tan E M. Rodnan G P. Garcia I, Moroi Y. Fritzler M J, Peebles C. Diversity of antinuclear antibodies in progressive systemic sclerosis. Anticentromere antibody and its relationship to CREST syndrome. Arthritis Rehum 1980; 23: 617-25.

3 Fritzler M J, Kinsella T D, Garbutt E. The CREST syndrome: a distinct serologic entity with anticentromere antibodies. $A m \mathrm{~J}$ Med 1980: 69: 520-6.

4 Kallenberg C G M. Pastoor G W. Wouda A A. The T H. Antinuclear antibodies in patients with Raynaud's phenomenon: clinical significance of anticentromere antibodies. Ann Rheum Dis 1982; 41: 382-7.

5 Catoggio L J. Bernstein R M. Black C M. Hughes G R V. Maddison P J. Serological markers in progressive systemic sclerosis: clinical correlations. Ann Rheum Dis 1983; 42: 23-7.

6 McCarty G A. Rice J R. Bembe M L. Barada F A Jr. Anticentromere antibody. Clinical correlations and association with favourable prognosis in patients with scleroderma variants. Arthritis Rheum 1983; 26: 1-7.

7 Tuffanelli D L. Mckeon F. Kleinsmith D M. Burnham T K. Kirschner $M$. Anticentromere and anticentriole antibodies in the scleroderma spectrum. Arch Dermatol 1983; 119: 56(1)6.

8 Tan E M. Cohen A S. Fries J F. et al. 1982 revised criteria for the classification of systemic lupus erythematosus. Arthritis Rheum 1982: 25: 1271-7.

9 Ropes M W. Bennett G A. Cobb S. Jacox R. Jessar R. 1958 revision of diagnostic criteria for rheumatoid arthritis. Bull Rheum Dis 1958: 9: 175-6.

10 Research Committee for Sjögren's syndrome. Diagnostic criteria for Sjögren's syndrome. Annual Report of the Ministry of Health and Welfare, Japan. 1978: 6.

11 Shearn M A. Sjögren's syndrome. Philadelphia: Saunders, 1971: 11.

12 Nishikai M. Reichlin M. Heterogeneity of precipitating antibodies in polymyositis and dermatomyositis. Characterization of the Jo-1 antibody system. Arthritis Rheum 1980; 23: 881-8.

13 Towbin H T. Staehelin T. Gordon J. Electrophoretic transfer of proteins from polyacrylamide gels to nitrocellulose sheets: procedure and some applications. Proc Natl Acad Sci USA 1979: 76: 4350-4. 
14 Douvas A S, Achten M, Tan E M. Identification of a nuclear protein (Scl-70) as a unique target of human antinuclear antibodies in scleroderma. J Biol Chem 1979; 254: 10514-22.

15 Mckeon F D, Tuffanelli D L, Fukuyama K, Kirschner M W. Autoimmune response directed against conserved determinants of nuclear envelope proteins in a patient with linear scleroderma. Proc Natl Acad Sci USA 1983; 80: 4374-8.

16 Moroi Y, Hartman A L, Nakane P K, Tan E M. Distribution of kinetochore (centromere) antigen in mammalian cell nuclei. $J$ Cell Biol 1981; 90: 254-9.

17 Habets W J, Derooij D J, Salden M H, et al. Antibodies against distinct nuclear matrix proteins are characteristic for mixed connective tissue disease. Clin Exp Immunol 1983; 54: 265-76.

18 Tan E M, Kunkel H G. Characterizations of a soluble nuclear antigen precipitating with sera of patients with systemic lupus erythematosus. J Immunol 1966; 96: 464-71.

19 Mattioli M, Reichlin. Characterization of a soluble nuclear ribonucleo protein antigen reactive with SLE sera. J Immunol 1971; 107: 1281-90.

20 Clark G, Reichlin M, Tomasi T B Jr. Characterization of a soluble cytoplasmic antigen reactive with sera from patients with SLE. J Immunol 1969; 102: 117-22.

21 Alspaugh M A, Tan E M. Antibodies to cellular antigens in Sjögren's syndrome. J Clin Invest 1975; 55: 1067-73.

22 Mattioli M, Reichlin M. Heterogeneity of RNA protein antigens reactive with sera of patients with systemic lupus erythematosus; description of a cytoplasmic nonribosomal antigen. Arthritis Rheum 1974; 17: 421-9.
23 Miyawaki S, Kohmoto K, Kurata N, Ofuji T. Identification and characterization of two new soluble nuclear antigens reactive with sera of patients with connective tissue diseases. Arthritis Rheum 1978; 21: 803-10.

24 Miyachi K, Tan E M. Antibodies reacting with ribosomal ribonucleoprotein in connective tissue diseases. Arthritis Rheum 1979; 22: 87-93.

25 Wolfe J F, Adelstein E, Scharp G C. Antinuclear antibody with distinct specificity for polymyositis. J Clin Invest 1977; 59: 176-8.

26 Winn D M, Wolfe J F, Harmon D, Scharp G C. Characterization of a distinct acidic protein antigen (MA) and clinical findings in systemic lupus erythematosus patients with MA antibodies. J Clin Invest 1979; 64: 820-3.

27 Nishikai M, Reichlin M. Purification and characterization of a nuclear non-histone basic protein (Mi-1) which reacts with anti-immunoglobulin sera and the sera of patients with dermatomyositis. Mol Immunol 1980; 17: 1129-41.

28 Mimori T, Akizuki M, Yamagata H, Inada S, Yoshida S Homma M. Characterization of a high molecular weight acidic nuclear protein recognized by autoantibodies in sera from patients with polymyositis-scleroderma overlap. J Clin Invest 1981; 68: 611-20.

29 Tojo T, Kaburaki J, Hayakawa M, Okamoto T, Tomii M, Homma M. Precipitating antibody to a soluble nuclear antigen ' $\mathrm{Ki}$ ' with specificity for systemic lupus erythematosus. Ryumachi 1981; 21 (suppl): 129-34. 